\title{
Diáspora y libertad: el legado de Irena Majchrzak a la educación indígena en México
}

\author{
REBECA BARRIGA VILLANUEVA
}

\author{
Sólo deja huella lo que se aprende \\ con emoción: la intensidad afectiva del \\ encuentro es la medida de la verdadera \\ integración perdurable del saber. La \\ sensibilidad se educa en el ejercicio \\ de la libertad creativa.
}

Julieta Campos (1988)

Preámbulo: ¿por qué Irena Majchrzak aquí?

Diaspora and Fredom: The Legacy of Irena Majchrzak to Mexican Indigenous Education

\section{Rebeca Barriga Villanueva \\ El Colegio de México, Distrito Federal, México barriga@colmex.mx}

Desacatos 48, mayo-agosto 2015, pp. 158-167
1 Julieta Campos conoció el trabajo de Irena. Como esposa del gobernador de Tabasco,
le propuso elaborar un proyecto educativo para los niños indígenas de la entidad que
vivían en los albergues que ella conocía. El prólogo que hace a la segunda edición
de Cartas a Salomón... refleja la gran admiración que tenía hacia Irena debido a la
fructífera labor que realizó entre los niños chontales y choles de Tabasco. Gracias
a su conocimiento de María Montessori y Simona, una niña chontal, Irena empezó
a pergeñar en Guaytalpa, Nacajauca, su "Método de lectura y escritura", que se
consolidaría años más tarde en Nombrando al mundo. El encuentro con la lengua
escrita a partir del nombre propio (Majchrzak, 2004). Para tener una visión pano-
rámica de este método, véase Barriga (2005). na respuesta indiscutible es porque, aunque su acción educativa se inserta en primera instancia en el paradigma bilingüe bicultural, Irena anuncia y preconiza con sus ideas y acciones una verdadera concepción de la interculturalidad. ¿Quién es Irena Majchrzak? Ida Englard Moskowicz, Irena Kisielwska, Irena Majchrzak, polaca, judía, mujer vital, sensible, enérgica, crítica, bondadosa, activa, creativa, valiente, socióloga, educadora, con una penetrante visión de la realidad 
humana y de sus inefables poderes de destrucción y construcción. Hecha en el dolor del Holocausto y en los entresijos del exilio, legó a México una forma liberadora y auténtica de interactuar con el indígena y una propuesta metodológica emanada de su paradójica experiencia: el nombre propio como disparador de la lectura y la escritura. Ese nombre que nos identifica con nosotros mismos y que nos hace presentes o ausentes en el mundo que habitamos. El nombre que Irena tuvo que cambiar para sobrevivir al exterminio.

Irena vino a México por primera vez como esposa del embajador de Polonia, Ryszard Majchrzak, en 1966. Su fina sensibilidad la hizo descubrir muy pronto a los actores y las realidades que pincelarían su invaluable legado a México y a sus controvertidas políticas lingüísticas, tan fuertes en su discurso, tan endebles en la acción. Irena se adelantó a su tiempo, vivió en su itinerario mexicano una verdadera interculturalidad y fue una promotora a ultranza del "buen vivir"2 del otro, del indígena, visto como la expresión explícita y contundente de una diversidad armónica y enriquecedora que potencia en sí misma la posibilidad de igualdad, de autonomía, y por ende, de bienestar social entre los hombres y las culturas.

En este trabajo me limitaré a espigar en las Cartas a Salomón. Reflexiones acerca de la educación indígena, primera obra de Irena Majchrzak en México, en la que se entretejen sus propios hilos emocionales y profesionales con los de la realidad educativa indígena mexicana. Mi objetivo final es mostrar con nitidez la calidad de su legado material e intangible en elámbito de la política lingüística de México.

\section{Las huellas de una vida}

Resulta interesante observar cómo las partes más sobrecogedoras de la biografía de Irena son la clave para comprender su cercanía con los indígenas y su intrincada y diversa realidad:
Los indios, me decía, son tan huérfanos como yo. Aquí nadie puede dejar de ser distinto porque los que lo intentan, se desdibujan prácticamente en nada y queda nadie para preparar el huitlacoche, sembrar de incienso la milpa y prender la veladora (Ashwell, 2011).

Irena Majchrzak nació el 26 de septiembre de 1927 en Piotrkrów, Polonia. Su verdadero nombre era Ida Englard Moskowicz. Durante la ocupación alemana en Polonia se refugió en un convento católico en Ignaców, donde tuvo que esconder su identidad y cambiar su nombre por el de Irena Kisielwska. Al casarse adoptó el apellido Majchrzak de su esposo. Subrayo lo simbólico de este imperativo cambio de nombres por el significado profundo en la vida de Irena: el nombre propio sería, con el tiempo, precisamente en el tiempo mexicano, el motor de su obra y su legado reivindicador del indígena. La pérdida del nombre y su identidad, la hégira y el exilio serán los elementos dramáticos disparadores de un peculiar mimetismo entre Irena y el indígena mexicano. En los albergues de las comunidades indígenas que visitó, más que evaluar, revivió de muchas formas los rasgos de un exilio obligado, una identidad enmascarada y la ansiedad de no hablar la lengua propia. Irena fusionó su vida con la vida indígena en un todo inseparable:

Yo, una polaca, ando por esta tierra buscando la comunicación humana en un lenguaje que no es ni polaco, ni español, ni nahua, ni mazateco [...] mi único

El buen vivir o vivir bien se ha definido en las últimas décadas como "una alternativa civilizatoria que se fundamenta en la construcción de relaciones armoniosas y de interdependencia entre lo viviente: seres humanos entre sí, seres humanos y naturaleza. Para hacerlo, coloca a la diversidad como consustancial" (León, 2010: 8). Irena, casi 25 años antes, se distingue con su pensamiento y acción como defensora a ultranza de esta postura de armonía y bienestar como condición imprescindible para una educación indígena bien entendida. 
método será exponerme al "choque de culturas", al azar de los encuentros humanos siempre únicos, siempre definidos por las culturas y las experiencias vitales de los participantes (Majchrzak, 1988: 23).

Irena murió el 25 de febrero de 2011 después de una agitada vida, plena y generosa. Hoy yace en el cementerio judío de Varsovia, donde su hijo Marek cumplió con su última voluntad (Ashwell, 2011).

\section{Paralelismos: la experiencia mexicana}

Irena Majchrzak llegó a México en 1966. Su rico bagaje intelectual y su formación de socióloga le abrieron de inmediato mil interrogantes en torno a la compleja realidad mexicana. De ahí su pronta incursión en las clases de Gonzalo Aguirre Beltrán y su amistad con jóvenes antropólogos: Mercedes Olivera, Margarita Nolasco, Guillermo Bonfil, Salomón Nahmad y Carlos Incháustegui. Además de presenciar la sacudida que significó el movimiento estudiantil del 68 para la sociedad mexicana, tuvo también en esta época sus primeros acercamientos a la realidad indígena de México: con los tarascos de Cherán, Michoacán, y con los mazatecos de Huautla de Jiménez, Oaxaca. Años más tarde, ya en su papel de observadora, retomaría el hilo de las experiencias con estas dos etnias, cuyas estructuras culturales son diametralmente opuestas.

Casi 20 años después, de nuevo impelida por el miedo a la persecución y a la privación de su libertad a causa de la crisis de Polonia con la Unión Soviética, Irena le pidió a su amigo Salomón Nahmad, ya director general de Educación Indígena de la Secretaría de Educación Pública (SEP), "pasar un tiempo colaborando en Educación Indígena y de esta manera poder salir de su país y al mismo tiempo, cumplir con su sueño de poder trabajar en las comunidades indígenas" (Nahmad, 2012: 2). La invitación no se hizo esperar, la labor encargada estaba hecha a la medida de la experiencia vital de Irena. Relata Nahmad:

Le pedimos a Irena que realizara un diagnóstico técnico pedagógico, desde una perspectiva externa al país, para detectar si se cumplían los objetivos que en ese entonces se realizaban para una educación bilingüe bicultural sobre la base de cinco indicadores que permitieran medir la calidad de la educación:

1. Idioma en el que se imparte la enseñanza

2. Enseñanza de la lectoescritura

3. Existencia y elaboración de material didáctico bilingüe

4. Idioma empleado cotidianamente

5. Aprovechamiento de los niños albergados (Nahmad, 2012: 18-19) [las cursivas son mías].

Hago tres puntualizaciones importantes para entender a cabalidad el perfil humano y científico de Irena. La primera es la del carácter del diagnóstico que daría a sus visitas a los albergues indígenas. Por su estructura emocional nunca podría haber tenido un carácter meramente técnico:

Me cuesta mucho trabajo retener en la memoria las informaciones contenidas en los estudios de ciencias sociales, en las que la materia de la existencia humana está presentada en forma de modelos teóricos y datos estadísticos. Tal vez en esta deficiencia mía, trato de memorizar las caras humanas, las miradas, las sonrisas, la palabra de una conversación común (Majchrzak, 1988: 22-23).

La segunda es en torno a la petición de que Irena realizara su diagnóstico desde una "perspectiva externa”. Irena no podría lograrlo, pues para ella era condición insoslayable crear una empatía total con la cultura estudiada para lograr un conocimiento real de su naturaleza intrínseca. Además, a partir del pasado de Irena, la imbricación gueto-albergue estaría siempre presente en su epidermis. Su perspectiva sería 


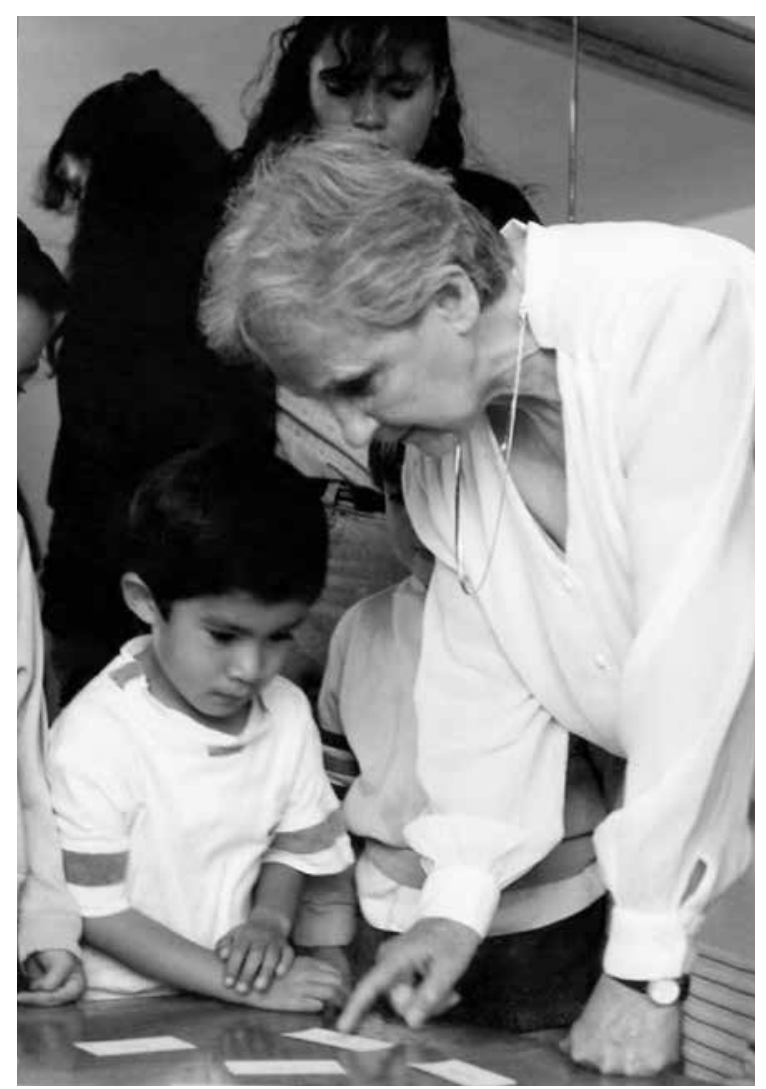

Cortesía de María Bertely.

entonces desde dentro. La última puntualización que hago está en relación con el valor -implícito o explícito- que Nahmad le confirió al indicador "idioma”. Como siempre, se busca dar con el secreto de una enseñanza idónea que logre entramar la lengua materna con la avasalladora presencia del español, el cual, por un lado, margina otros factores fundamentales que se superponen con la lengua, y por el otro, desconoce la realidad de un jabonoso bilingüismo. Los resultados en aquel momento, como otros del pasado y en este presente, fueron magros y contradictorios, con una tendencia notoria: el desplazamiento de las lenguas indígenas por el español.

Irena se convirtió así en la observadora, la evaluadora, la crítica sensible y aguda de la política lingüística mexicana de aquel momento. Peregrinar por el México indígena y vivir la realidad de sus comunidades desde dentro le permitió empatizar con los problemas de cada comunidad visitada y plasmar sus pensamientos y reflexiones de manera original:

\begin{abstract}
Hoy se ha decidido la forma del documento que me habías pedido [...]. Viajé por el desierto de Sonora, las montañas que casi te cierran y abren el horizonte y que en esta tierra casi despoblada, establecen una medida muy particular para evaluar los problemas humanos. En este camino comencé una conversación mental contigo. Y fue así como concebí las Cartas a Salomón [...]. Y ahora yo, que con tanta alegría acepté tu invitación, me siento oprimida por la responsabilidad (Majchrzak, 1988: 17-18) [las cursivas son mías].
\end{abstract}

El epistolario le permitió a Irena un especial acercamiento a la realidad narrada. El canon de una carta le consintió una postura humana como punto de partida: "algo me impide tratar al ser humano como el objeto de cualquier estudio como a un simple informante e instrumento que sirve para satisfacer el interés, digamos, científico, del estudioso"(Majchrzak, 1988: 22).

\section{Cartas a Salomón. Reflexiones acerca de la educación indígena}

Este singular libro está formado por 12 cartas atravesadas en su estructura esencial por la educación, las lenguas maternas —orales o escritas - y la diversidad de culturas, ejes rectores del pensamiento y el sentimiento de Irena Majchrzak. En efecto, estas cartas le ofrecen un amplio espacio para la introspección y la reflexión: "más que nada, quiero divagar sobre los problemas de la comunicación y el entendimiento, con o sin el conocimiento de un idioma común" (Majchrzak, 1988: 23). No deja de llamar la atención esta última afirmación que pone de relieve la jerarquía de valores para Irena. 
Entre los intersticios que permiten las paradójicas y encontradas emociones de la alegría y la opresión, Irena recorrió la geografía mexicana de norte a sur, de Sonora a Quintana Roo, donde los niños, sometidos a las inclemencias del calor seco del desierto sonorense o del sofocante calor húmedo de Tabasco y Quintana Roo, recibían una pretendida educación bilingüe y bicultural. En cada lugar, una de las preocupaciones permanentes de Irena era el hábitat de las comunidades indígenas y su papel crucial en la organización mental y espiritual de los habitantes de cada etnia:

"Cambiar o no cambiar", he aquí la alternativa
hamletiana que se plantea todo aquel que trabaja
en la materia sutil del medio ecológico y de la vida
humana [...]. qué hacer en los casos en que el medio
ambiente ya está alterado y el estilo de vida tradi-
cional ya no es el adecuado (Majchrzak, 1988: 76).

Observó cuatro comunidades y los albergues infantiles en Sonora: Desierto, Hermosillo, El Paso, Álamos y Mesa Colorada; una en Pátzcuaro, Michoacán; la comunidad de Huautla de Jiménez, en Oaxaca; Villahermosa y Nacajuca, en Tabasco, y Felipe Carrillo Puerto, en Quintana Roo. Pueblan sus cartas las voces de niños y maestros hablantes de las lenguas mayo y pápago, yaqui, seri, guarijío, tarasco, chontal y maya, lenguas estructuralmente diferentes y pertenecientes a muy distintas familias. Esta dispersión territorial y lingüística favoreció, desde ya, sus reflexiones, pues le permitió apreciar in situ los problemas de cada localidad y tratarlos como distintivos de esa comunidad, porque ninguna es igual a otra: "Cada viaje me llevaba a un mundo distinto, por el sabor y la vida cultural del grupo étnico que había visitado [...]. En todas estas regiones visité las escuelas, entré a los albergues y conversé con los maestros" (Majchrzak, 1988: 103). Aquí, las particularidades adquirieron valor y un rasgo imprescindible para entender a cabalidad el problema indígena mexicano: cada comunidad es en sí misma un cúmulo de verdades que no necesariamente son parte de las verdades de otra comunidad. Irena desveló estas verdades con gran acierto, pues más allá de la diversidad evidente, hay una unidad inexplicable en el sistema educativo: "pese a la variedad de regiones y de culturas étnicas, el sistema escolar vive su propia problemática, común para todos los lugares visitados" (Majchrzak, 1988: 103).

En lo que sigue, me limitaré a espigar en estas cartas y a seleccionar sólo algunas de las partes más sobresalientes que revelan la penetrante mirada de Majchrzak sobre esta increíblemente uniforme realidad educativa y social de las comunidades indígenas de México. En la carta escrita en el desierto de Sonora no parece fortuito que Irena hiciera un acertado resumen de las políticas indígenas de México, ambivalentes y contradictorias, como punto de partida de su evaluación:

La política hacia los indígenas durante muchos años fue la aculturación y la integración a la vida nacional [...] una política etnocida era al mismo tiempo, la manera de formar una nación nueva: la mexicana. Lo que unos ven como etnocidio para otros fue un acto de creación y transformación (Majchrzak, 1988: 18-19).

Tampoco es fortuito que pusiera el dedo en la llaga del problema lingüístico eterno desde la primera estación:
Al acercarme a la problemática de la educación bi- lingüe a los niños indígenas, siento todo el respeto y comprensión por la idea de enseñar en la lengua materna. Me parece lo más justo, tanto por la sobrevivencia del grupo étnico como por el respeto al mundo interior del niño (Majchrzak, 1988: 18-19) [las cursivas son mías].

Sobre la misma línea del pensamiento, en otra carta, escrita en Hermosillo, Irena describió la imperante gama de actitudes entre los grupos étnicos del territorio sonorense: los yaquis rebeldes se oponen, al 
igual que los seris autónomos, individualistas y agresivos, a la educación bilingüe; los guarijíos por su aislamiento no hablan español, así que los maestros que lo enseñan han de ser los mayos con otra sensibilidad y visión del mundo. ¿Cómo darles a todos los niños de estas diferentes etnias una educación viable si "la escuela misma, aun la bilingüe, constituye un peligro para la subsistencia de la entidad étnica"? (Majchrzak, 1988: 27).

Llaman la atención los resultados de las observaciones recogidas por Irena en El Paso, Álamos y Mesa Colorada, Sonora, pues "en ninguno de estos casos la enseñanza es bilingüe". En El Paso, los niños hablan español: "ninguno de los niños, en el salón de clases quería aceptar que sabía hablar o entendía mayo" (Majchrzak, 1988: 35). Qué pronto la realidad se hizo visible para Irena: escuelas ficticiamente bilingües, niños con una pérdida temprana de la lealtad étnica y negación de la identidad. En Pátzcuaro, la capacidad creativa y artística de los tarascos despertó en Irena una nueva inquietud que redundó en el rechazo por el tipo de educación propuesta por el gobierno:

\begin{abstract}
Salomón, ¿te das cuenta de que casi toda la discusión de cómo llevar a cabo la educación en las zonas indígenas gira únicamente alrededor del idioma en la enseñanza? [...] No obstante, quisiera llamar la atención sobre el hecho de que el sistema escolar opera en las zonas indígenas no solamente por medio del idioma, se opone al estilo de vida tradicional, to nulifica y a veces también lo destruye introduciendo nuevas formas arquitectónicas, muebles desconocidos, otras formas de dormir, de alimentarse (Majchrzak, 1988: 44-45) [las cursivas son mías].
\end{abstract}

Atinada observación de Irena que le permitió trascender la lengua, crucial, qué duda cabe, para mirar el problema con una lente más abarcadora. El arte, redentor y liberador, inherente a la esencia de los tarascos, es otro tipo fundamental para la supervivencia:

\begin{abstract}
El arte es un lenguaje, es un medio de expresión [...] el lenguaje del artista indígena contemporáneo (me refiero también al niño) no es realista. Su modo de ver y presentar el mundo sigue siendo mítico. ¿Qué se puede hacer para salvar y proteger este lenguaje? El problema es tanto más difícil y sutil ya que el arte no admite bilingüismo (Majchrzak, 1988: 51-52).
\end{abstract}

Las cartas que emergieron de la experiencia mazateca en Huautla son sumamente sugerentes, pues se tejieron alrededor de una doble experiencia: la de los hongos con efectos mágicos y surrealistas y la de la situación inmanejable de conflicto entre partidos políticos, maestros y padres de familia. Irena no pretendía explicar un problema que se le escapaba de las manos, pero sí aprovechó los pocos elementos que le ofrecía la realidad educativa para distinguir una ineludible realidad que era clara:

Ya hay muy pocos niños que hablan su lenguaje, que sus propios padres se dirigen a ellos en español. Aunque entre sí hablen en mazateco. Así quieren ahorrar a sus hijos dificultades y sufrimientos cuando vayan a la escuela; ni los mismos maestros bilingües hablan a sus hijos en mazateco, tampoco se preocupan por mantener vivo el idioma natal al que no llaman "idioma" sino "dialecto", convencidos de que la palabra "idioma" se reserva para las lenguas que tienen escritura y gramática (Majchrzak, 1988: 69).

En Villahermosa y Najacuja, Tabasco, lugar de chontales, las cartas son tan intensas como el clima. El bochorno asfixiante provocó en Irena una sensibilidad especial para concentrarse en el de papel de una biculturalidad destructiva e insensible a los valores culturales inherentes a las etnias:

Empiezo a pensar que este lugar es el ejemplo de cierto biculturalismo, resultado de la doble mutilación de las culturas en juego. La gente ya sabe leer 
pero no goza de la lectura y no la necesita; la gente suda y sufre, pero duerme en colchones importados en vez de usar petates de propia producción (Majchrzak, 1988: 74).

Sobre esta fallida biculturalidad, responsable indudable de la frustración, tristeza, resentimiento de los niños, sus padres y sus maestros, Irena encontró los vericuetos de una definición, acorde con la perspectiva con que se miraba:

La cultura es un conjunto de respuestas que un grupo étnico da a su ambiente ecológico. La civilización occidental entenderá por la palabra "responder": la acción de conquistar, vencer o transformar la naturaleza de acuerdo con los deseos de los humanos. La civilización indígena entiende por la palabra "responder" el acomodarse, convivir y hasta servirle a la naturaleza (Majchrzak, 1988: 79).

Esta mirada, un tanto azorada, se agudizó en Quintana Roo, en su visita a X-Cacal y Chocoh, a partir de las respuestas que los maestros bilingües le dieron sobre la expresión "educación bicultural": "dar un lugar adecuado a las costumbres de una etnia, más aún, hay que rescatar estas costumbres" (Majchrzak, 1988: 94). Irena concluyó que las costumbres son "escombros de una cultura desintegrada [...], las costumbres no crean una cultura. Percibo una cultura como un sistema coherente de creencias y valores" (Majchrzak, 1988: 94).

En la última carta, escrita en el Distrito Federal, se concentran en cuatro provocativos "acerca" las ideas un tanto utópicas de Irena, en una suerte de resumen honesto de lo visto y vivido. Los títulos son elocuentes y hablan por sí solos: "Acerca de los términos bilingüe y bicultural”, "Acerca de la necesidad de proteger la dignidad del niño indio", "Acerca de la necesidad de crear la conciencia geográfica", "Acerca de la necesidad de crear bibliotecas". Estos "acerca" buscaban revertir el camino trazado hasta ese momento por la política para comenzar otro que realmente concibiera el bilingüismo y la biculturalidad como el uso equilibrado de dos lenguas en contacto y la integración real de dos culturas - la nacional y la de una etnia en particular-, que combinara elementos culturales y valores. Respecto de la indianidad, Irena enfatizó la obligación inexcusable de la escuela de proteger los valores de la civilización india y de la cultura del grupo étnico al que pertenece el niño: "es muy importante hacer todo lo posible para que nunca desee rechazar su pasado" (Majchrzak, 1988: 109).

Conocer la imagen integral del territorio nacional con las peculiaridades de cada lugar para motivar que los niños, "pasajeros" continuos en un mundo de migración, tengan una conciencia geográfica que les haga distinguir la comunidad, la región, el país, el continente y el mundo: "sin la conciencia geográfica no puede darse la conciencia histórica ni de la nación ni del grupo étnico" (Majchrzak, 1988: 112). Por último, las bibliotecas, indispensables para Irena en una educación congruente, son el puente imprescindible entre el niño y la cultura universal, una forma de liberación de la creatividad y la imaginación que le dé sentido a la obsesión por la lectura obligatoria y carente de objetivos claros para los niños:

Como la escuela es compulsiva (enseñar, enseñar y nada más enseñar) quisiera subrayar que las bibliotecas escolares deben estar compuestas, no tanto por los libros de consulta sino por las lecturas de diversión, cuentos bellos, fantásticos, interesantes, lo que le valdría al niño el esfuerzo de aprender el alfabeto (Majchrzak, 1988: 113-114).

\section{El legado}

A lo largo de estas necesariamente someras reflexiones tejidas al hilo de las de Irena, he querido dejar ver la riqueza de su legado. Irena Majchrzack 
entendió a fondo las políticas lingüísticas mexicanas dedicadas a los indígenas. Su mirada empática no pudo ser ni complaciente ni paternalista. Su aguda capacidad de sentir al otro - al indígena- en sus necesidades más acuciantes le impidió enmascarar la realidad. Su momento histórico de acción fue el de una política sui generis en el que el segundo término de la ecuación bilingüe-bicultural complejizaba aún más las cosas. Si el bilingüismo era inalcanzable, lo bicultural era prácticamente incomprensible para quienes debían aplicarlo. Cuando lo hacían, caían en un folclorismo ramplón y empobrecedor. Como alternativa, Irena fue una auténtica promotora de la interculturalidad, entendida en su esencia prístina: visión profunda y genuina de la diversidad vertida en convivencia equilibrada y respetuosa de culturas y lenguas diferentes que se respetan y se dejan ser en la autonomía, lo que conduce a un buen vivir dentro de los parámetros de la propia cosmovisión. Irena buscó ver a los otros "como sujetos de cambio de su propio destino” (Majchrzak, 1988: 77). Sus Cartas a Salomón... dejan ver con naturalidad y contundencia la verdad de las comunidades indígenas, de los problemas de los maestros, de las actitudes los padres y de la vivencia en los albergues, hábitat cambiante de los niños, cuya dinámica transformaba poco a poco el paisaje primigenio de su cultura y desplazaba sutilmente su lengua materna. Con sus argumentos puso de manifiesto lo lábil de las políticas lingüísticas y culturales mexicanas hechas con promesas inalcanzables por una reiterada mistificación de la realidad. Lo notable es que Irena no se quedó atrapada en la denuncia improductiva. Ofreció, en cambio, salidas plausibles que ayudaron a rescatar el espíritu indígena y a preservar la integridad del niño. El mejor de estos caminos, qué duda cabe, fue ofrecer una vía posible de liberación, el de la lengua escrita:

Diría yo que el acto de la iniciación es un gesto mágico que introduce al niño en el mundo de la lengua escrita. E1 niño siente que por medio de la escritura puede ser representado. Percibe que él mismo puede ser escrito $y$ leído, ya que su nombre se compone de letras y en esta forma es introducido en el círculo de la comunicación que se realiza a través de la lengua escrita. El niño se percibe a sí mismo existiendo de dos formas, la física y la simbólica, y entiende que él, un pequeño que se llama por ejemplo Adrián, constituye el significado de la palabra Adrián (Majchrzak, 2004: 19) [las cursivas son de Majchrzak]. D

\section{Bibliografía}

Ashwell, Anamaría, 2011, “Irena Majchrzak”, en Dirección General de Educación Indígena, Secretaría de Educación Pública, disponible en línea: <http://basica.sep.gob.mx/dgei/pdf/inicio/personajes/IrenaMajchrzak.pdf>.

Barriga Villanueva, Rebeca, 2005, “El poder del nombre”, en Revista Mexicana de Investigación Educativa, vol. 10, núm. 27, pp. 1291-1294.

Campos, Julieta, 1988, “Prólogo”, en Irena Majchrzak, Cartas a Salomón. Reflexiones acerca de la educación indígena. Posdata desde Tabasco, seis años después, Gobierno del Estado de Tabasco, Villahermosa.

León, Irene, 2010, "Resignificaciones, cambios societales y alternativas civilizatorias", en Irene León (coord.), Sumak Kawsay/Buen vivir y cambios civilizatorios, Fundación de Estudios, Acción y Participación Social, Quito.

Majchrzak, Irena, 1988, Cartas a Salomón. Reflexiones acerca de la educación indígena. Posdata desde Tabasco, seis años después, Gobierno del Estado de Tabasco, Villahermosa.

— 2004, Nombrando al mundo. El encuentro con la lengua escrita a partir del nombre propio, Paidós, México.

Nahmad, Salomón, 2012, "Introducción”, en Irena Majchrzak, Cartas a Salomón. Reflexiones acerca de la educación indígena, Secretaría de Educación Pública-Dirección General de Educación Indígena/Gobierno del Estado de Yucatán/Centro de Investigaciones y Estudios Superiores en Antropología Social, México, pp. 13-27. 